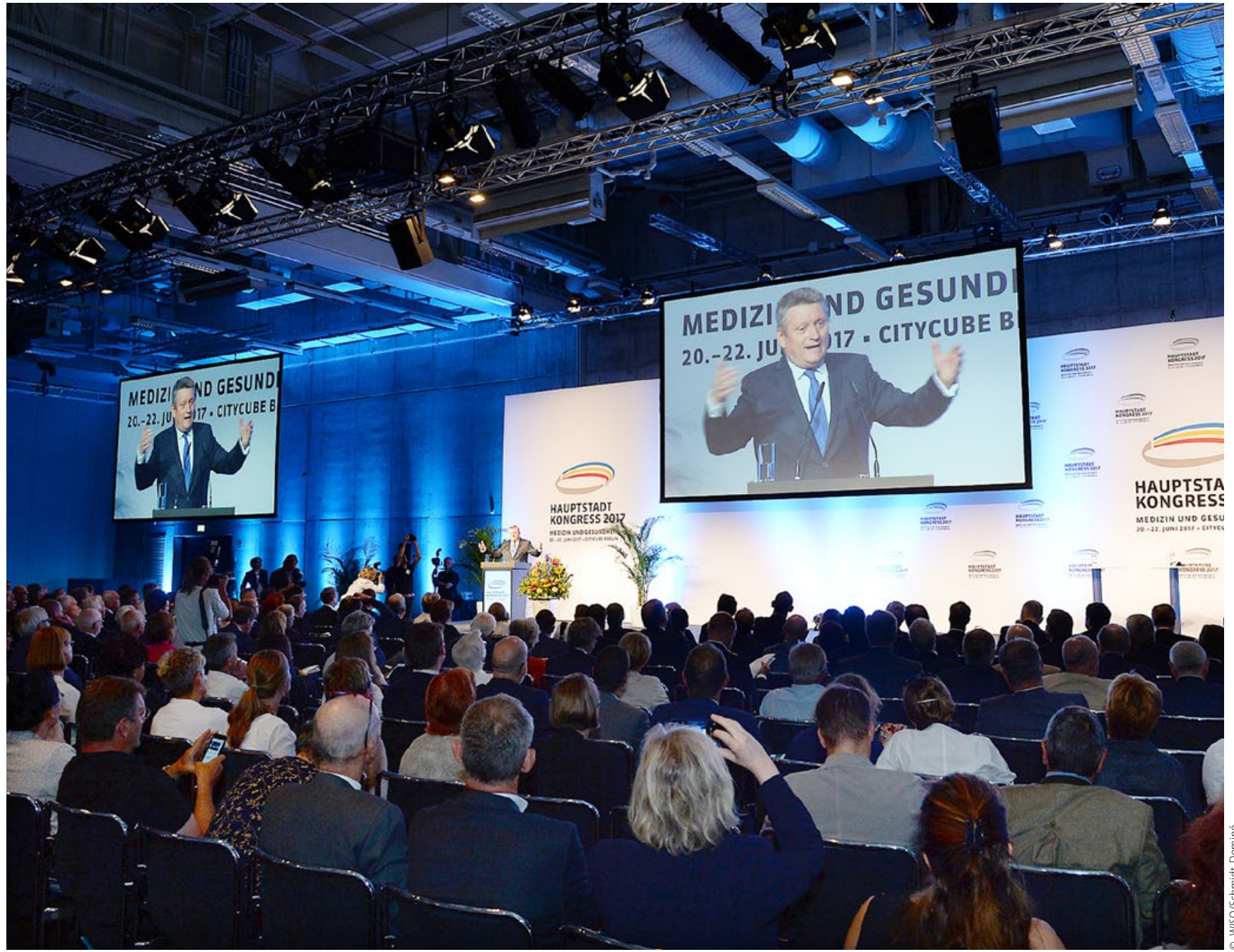

Hauptstadtkongress Medizin und Gesundheit

\title{
Gröhe fordert mehr Zusammenarbeit
}

Mehr Teambewusstsein im deutschen Gesundheitswesen hat Bundesgesundheitsminister Hermann Gröhe (CDU) im Juni auf dem Hauptstadtkongress Medizin und Gesundheit in Berlin gefordert. Er rief die Leistungserbringer auf, intensiver zu kooperieren.

Das Gesundheitswesen müsse sich daran orientieren, „dass aus den vielen, guten, ja Spitzenleistungen des deutschen Gesundheitswesens eine Mannschaftsleistung wird“, sagte Gröhe bei der Eröffnung des dreitägigen Kongresses. Der Minister betonte, alle Gesetze der ablaufenden Legislaturperiode hätten im Kern der Vernetzung gedient. So sei der mit dem Versorgungsstärkungsgesetz eingerichtete Innovationsfonds geschaffen worden, „damit statt Mauern Brücken zwischen den Sektoren gebaut werden“. Ziel sei „Vernetzung durch sektorübergreifende Versorgung“.

Aber auch die Zusammenarbeit zwischen Spezialkliniken und regionalen Krankenhäusern gehöre dazu. Durch digitale Vernetzung müsse künftig jeder Regelversorger in der Lage sein, das Wissen der Spitzenmedizin von einem Maximalversorger abzurufen, wobei „dann dank Telemedizin egal ist, wie weit er entfernt ist." Gröhe kritisierte die langsame Umsetzung solcher Zusammenarbeit in Deutschland: „Ich bedaure, dass das Thema Digitalisierung sehr zögerlich angegangen wird“, so der Minister wörtlich.

Der Hauptstadtkongress Medizin und Gesundheit fand zum 20. Mal statt. An dem Kongress mit zahlreichen Vorträgen und Diskussionsrunden nahmen mehr als 8.000 Vertreter aus Politik, Verbänden, Gesundheitswirtschaft und -management, Versicherungen, Wissenschaft, Medizin und Pflege teil. Das Motto lautete: „Qualität und nachhaltige Finanzierung“. 